\title{
ABRACE: 20 ANOS - CELEBRANDO A DIVERSIDADE
}

\author{
Marcilio de Souza Vieira
}

Universidade Federal do Rio Grande do Norte (UFRN)

\section{RESUMO}

O presente artigo traça um relato histórico da Associação Brasileira de Pesquisa e Pós-Graduação em Artes Cênicas (ABRACE), que em 2018 completou 20 anos de existência. Rememorar a trajetória da ABRACE em seus aspectos nostálgicos, políticos, éticos e estéticos foi a tônica dessa mesa comemorativa, que partilhou por meio da memória alheia a trajetória dessa Associação. Certamente, nessas memórias, fatos se perderam e outros foram esquecidos; pessoas desapareceram e foi selecionado aquilo que interessava que fosse lembrado. Além dessas memórias, este artigo traz um relato sucinto do que a Associação tem realizado além das reuniões científicas e dos congressos, bem como levanta a questão de como a ABRACE tem discutido a docência e o fortalecimento do ensino de Arte, em especial das Artes Cênicas no país.

Palavras-chave: ABRACE. Artes Cênicas. História. Memória. Pesquisa. 
o ano de 2018, a Associação Brasileira de Pesquisa e Pós-Graduação em Artes Cênicas (ABRACE) completou 20 anos de existência. Fundada a partir de uma demanda da área de Artes Cênicas para socialização das pesquisas oriundas dos Programas de Pós-Graduação em Artes Cênicas, que concentram pesquisas nas áreas de Teatro, Dança, Performance, Circo, Teoria das Artes Cênicas, a Associação foi criada em 21 de abril de 1998, em Salvador, Bahia (com apoio do CNPq e do CADCT/BA). Esse processo contou com uma ampla participação de lideranças representativas da área de Artes Cênicas de todo o Brasil e teve no I Congresso (São Paulo) o primeiro ponto forte de sua história (http://portalabrace.org/4/). ${ }^{1}$

Celebrar a diversidade foi o tema que norteou as palestras, as mesas temáticas, os workshops, bem como os Grupos de Trabalho nesse X Congresso realizado na cidade de Natal (RN). Houve na programação do evento uma homenagem/mesa com os ex-presidentes que estiveram à frente da Associação em suas reuniões científicas e congressos ocorridos desde o ano de 1998, quando da fundação da ABRACE. Participaram dessa mesa comemorativa os ex-presidentes André Luiz Antunes Netto Carreiras (2002-2004), Maria de Lourdes Rabetti (2004-2006), Fernando Antonio Mencarelli (2006-2008), Luiz Fernando Ramos (2009-2010), Marta Isaacsson de Sousa e Silva (2011-2012), Arnaldo Leite de Alvarenga (2013-2014), Narciso Laranjeira Telles da Silva (2015-2016) e Robson Carlos Haderchpek, atual presidente (20172018). Sérgio Coelho Borges Farias representou as gestões 1998-2000 e 2000-2002, como tesoureiro. As reuniões científicas e os congressos ocorreram respectivamente nas cidades de Florianópolis, Rio de Janeiro, Belo Horizonte, São Paulo, Porto Alegre, Belo Horizonte, Uberlândia e Natal. Nas gestões 1998-2000 e 2000-2002, ocorreram nas cidades de São Paulo e Salvador, respectivamente.

Rememorar a trajetória da ABRACE em seus aspectos nostálgicos, políticos, éticos e estéticos foi a tônica dessa mesa comemorativa que partilhou, por meio da memória alheia, a trajetória dessa Associação. Certamente, nessas memórias, fatos se perderam e outros foram esquecidos; pessoas desapareceram (a exemplo do presidente Armindo Bião, que geriu a ABRACE nas duas primeiras gestões) e foi selecionado aquilo que interessava que fosse lembrado.

Nessa mesa comemorativa, a memória foi seletiva. Lembrar-se de alguma coisa é lembrar-se de si. Quando rememoramos fatos passados, quando interpretamos fatos presentes, quando um sistema complexo de representações ocupa nossa inteligência, sentimos que é possível uma fenomenologia da lembrança e uma consciência íntima do tempo (Ricoer, 2007).

Somos aquilo que recordamos, e a memória é aquisição, formação, conservação e evocação de informações que são aprendidas, lembradas, recordadas por nós. Só lembramos daquilo que gravamos, aquilo que foi aprendido. Dessa forma, o passa-

1 Parte deste texto foi apresentado como palestra na mesa-redonda Associações Nacionais: conexões entre associação, formação e políticas educacionais, no XXVIII CONFAEB/VI, Congresso Internacional da Federação de Arte/Educadores, que aconteceu em Brasília entre os dias 6 e 9 de novembro de 2018. 
do, nossas memórias, nossos esquecimentos voluntários, não só nos dizem quem somos, mas também permitem que nos projetemos rumo ao futuro, isto é, dizem quem poderemos ser (Izquierdo, 2002).

Ainda na seara da diversidade celebrada nesses 20 anos de existência e resistência em tempos sombrios, em abismos de flores, o X Congresso congregou artistas-pesquisadores-artistas para discutir a diversidade e suas pluralidades quando tematizou/refletiu/discutiu a mulher indígena no contexto da América Latina, o feminismo nas vozes de mulheres artistas e ativistas, as heranças africanas e as culturas tradicionais e identidades. Celebrar a diversidade nesse $\mathrm{X}$ Congresso significou também reconhecer um esforço de 20 anos de luta e resistência dos pesquisadores da área das Artes Cênicas pelo direito de existir, de fazer arte dentro e fora da universidade, de gerar conhecimento específico na área cênica. A diversidade e a pluralidade de saberes em campo expandido, num diálogo com outras áreas, como a Sociologia, a Antropologia, a Educação, a Política, a Psicologia etc. Para a ABRACE, pensar a pluralidade é pensá-la em diálogo com o outro, com as áreas correlatas e, assim, ampliar as percepções da arte, da cultura e da sociedade (Abrace, 2018).

Tratar de 20 anos de existência e resistência é rememorar os passos dados por essa associação e a composição de seus Grupos de Trabalhos, que foram se modificando ao longo do tempo de acordo com as necessidades dos sócios efetivos, colaboradores e estudantes.

A ABRACE organiza encontros anuais que aparecem, num ano, como reuniões científicas e, no outro, como congressos nacionais. Desde o seu início, mantém atividade constante e tem se convertido em um marco de exposição da pesquisa teatral no Brasil. Os interesses principais da instituição são: incentivar a pesquisa, congregar os programas de pós-graduação brasileiros, representar seus associados ante instituições e agências de financiamento, promover reuniões científicas e artísticas, divulgar estudos, fomentar a troca e a cooperação científica e artística entre os grupos de pesquisa, programas de pós-graduação e de graduação, identificar temas prioritários de pesquisa, prestar serviços técnicos e viabilizar instrumentos jurídicos para a realização destes objetivos. Tudo isso, obviamente, dentro do exercício das Artes Cênicas, o que contempla Teatro e Dança (ABRACE, 2012). Nesse panorama, o esforço dos pesquisadores do campo brasileiro de Artes Cênicas se traduz num movimento com uma alta visibilidade que, aliás, tem contribuído à validação de seus produtos de criação como elementos que podem medir a capacidade e a qualidade da produção de conhecimento de seus pesquisadores.

Logo em sua primeira edição, a Associação questionou-se em sua temática: Quem Somos? Esse tema perpassou as discussões dos Grupos de Trabalhos que foram criados ainda nos idos de 1999, e a temática possibilitou um panorama do que se estava produzindo e pesquisando em Artes Cênicas no Brasil. O eixo de trabalho naquele congresso foi construir um mapa da pesquisa e da pós-graduação no país.

No ano seguinte, em 2000, ocorreu a I Reunião Científica, resultando em ricas discussões sobre as pesquisas na área. Os debates acerca da implantação e da 
organização de Grupos de Trabalho (GTs) na ABRACE, assim como as 32 comunicações apresentadas durante a I Reunião, possibilitaram um amplo diagnóstico das perspectivas para a pesquisa de Graduação e Pós-Graduação em Artes Cênicas no Brasil (Abrace, 2000).

A temática central do II Congresso, ocorrido no ano de 2001, foi a questão "Como Pesquisamos?". Os diversificados debates e discussões suscitados por essa questão ocorreram na forma de mesas-redondas, conferências, performances, espetáculos e demais experimentos cênicos, bem como na forma de comunicações apresentadas no âmbito dos sete Grupos de Trabalho da entidade, a saber: GT Dramaturgia: tradição e contemporaneidade; GT História das Artes e do Espetáculo; GT Processos da Comunicação e Expressões Cênicas; GT Pedagogias do Teatro \& Teatro na Educação; GT Territórios e Fronteiras; GT Pesquisa de Dança no Brasil e GT Teatro Brasileiro (Abrace, 2001).

Verificou-se que o Congresso acolheu um número significativo de professores, artistas, estudantes e pesquisadores dos programas brasileiros e estrangeiros de pesquisa e Pós-Graduação em Artes Cênicas, computando cerca de 40 universidades e núcleos de pesquisa envolvidos (Abrace, 2001).

A II Reunião Científica foi realizada no Rio de Janeiro, em 2002, tendo a UFBA, a UNIRIO, a UFF e a UFRJ como anfitriãs, com o apoio do CNPq, da CAPES e da FAPESB/ BA. Na ocasião, foram redefinidos os critérios conceituais e operacionais para a estruturação das novas coordenações dos Grupos de Trabalho e foram avaliados o incremento e o intercâmbio das parcerias institucionais e grupais.

A realização do III Congresso na cidade de Florianópolis, no ano de 2003, teve o Programa de Pós-Graduação em Teatro da Universidade do Estado de Santa Catarina (UDESC) como anfitrião e consolidou o esforço conjunto da sua Diretoria e de toda a comunidade associada (cerca de 350 pessoas e cinco programas), com o apoio da FUNCITEC/SC, do CNPq e da CAPES, por meio do PROAP, das universidades representadas e de outras instituições de amparo à pesquisa (Abrace, 2003).

Com a multiplicidade de ângulos, recortes e objetos que a tradição e a contemporaneidade da área de Artes Cênicas tornam previsíveis, o III Congresso da Associação contemplou as diversificadas questões culturais, estéticas e processuais emergentes no universo acadêmico e delimitou as linhas de ação da Associação para o biênio 2004-2006.

O III Congresso representou a quinta oportunidade de encontro e de amadurecimento da área de pesquisa em Artes Cênicas no Brasil. Nessa ocasião, foram discutidos, além das diferentes investigações levadas a cabo no interior dos Grupos de Trabalho (GTs), a estrutura de funcionamento da Associação com a criação de novos GTs e delineamentos gerais do trabalho da Associação. No III Congresso de Florianópolis, a ABRACE instituiu em sua estrutura os GTs: Dramaturgia - Tradição e Contemporaneidade, História das Artes do Espetáculo, Pedagogia do Teatro, Pesquisa de Dança no Brasil, Processos de Criação e Expressão Cênicas, Territórios e Fronteiras, Teatro Brasileiro, Estudos da Performance, Teorias do Espetáculo e da Recepção, Dança e Novas Tecnologias (Abrace, 2003). 
Em 2004 foi realizada a III Reunião Científica da Associação no Rio de Janeiro, na qual a nova diretoria do biênio 2004-2006 deliberou sobre a organização do IV Congresso, que foi realizado na UNIRIO. O IV Congresso, com o tema "'Os trabalhos e os dias"' das artes cênicas: ensinar, fazer e pesquisar dança e teatro e suas relações, teve lugar no Centro de Artes e Letras da UNIRIO, no Rio de Janeiro. Foram publicados 230 textos completos nos Anais - Memória ABRACE X. Além dos Anais, foi lançada a publicação Memória ABRACE IX, e os excelentes resultados percebidos no IV Congresso demonstraram claramente a representatividade e a solidez da Associação.

A IV Reunião Científica da Abrace foi realizada em Belo Horizonte, nos dias 5 e 6 de junho de 2007, tendo como anfitrião o Programa de Pós-Graduação em Artes da Escola de Belas Artes da Universidade Federal de Minas Gerais, com o apoio da Universidade Federal de São João del-Rei, da Universidade Federal de Uberlândia e da Universidade Federal de Ouro Preto. A IV Reunião Científica contou com a presença expressiva dos associados, tendo sido realizadas reuniões dos Grupos de Trabalho da ABRACE (11 grupos a partir desta reunião, quando foi criado o GT de Etnocenologia) e reuniões de avaliação do percurso da ABRACE, que completava, na época, 10 anos de atividade (Abrace, 2007).

O V Congresso Brasileiro de Pesquisa e Pós-Graduação em Artes Cênicas foi realizado em Belo Horizonte em 2008. O objetivo geral do V Congresso foi compor um amplo painel de conferências, mesas-redondas e comunicações que possibilitassem conhecer, discutir e difundir os avanços e o quadro atual das pesquisas e da pós-graduação em relação ao tema "Criação e Reflexão Crítica". O V Congresso contou com aproximadamente 670 inscritos e 450 trabalhos apresentados nos 11 Grupos de Trabalho da ABRACE, além de conferências e mesas-redondas.

A V Reunião Científica da ABRACE ocorreu no Departamento de Artes Cênicas da Escola de Comunicações e Artes da Universidade de São Paulo, com o apoio do Programa de Pós-Graduação em Artes Cênicas da USP, da Comissão de Pós-Graduação da ECA-USP e da Pró-Reitoria de Pós-Graduação da USP. A V Reunião Científica deu um salto organizativo na ABRACE, pois implicou a publicação dos anais em versão eletrônica, disponíveis no sítio da Associação e na consolidação do quadro associativo.

Dados esses dez primeiros anos da produção científica da Associação, pode-se dizer ela foi ganhando experiência no fazer e realizar seus congressos e reuniões. Associamos à essa experiência o que Larrosa (2002) expõe quando diz que essa, quando bem utilizada, produz significativas vivências e que precisa ser compartiIhada. Logo, experiência dos sentidos das ações e dos fazeres cotidianos; os sentidos de expertise, de repetição e domínio da ação; as (im)possibilidades de comunicabilidade do vivido; os impactos, os afetos; as relações entre vivência e experiência vicária. Tal sentido da experiência tem a ver com a legitimidade e a dignidade, com amplitude e precisão; com o saber da experiência como "[...] um saber particular, subjetivo, relativo, contingente, pessoal [...] que não pode separar-se do indivíduo concreto que o encarna" (Larrosa, 2002, p. 27). 
A experiência tem papel formador e é parte constituidora do sujeito. Ela envolve fatores que, segundo Larrosa (2002), não podem ser reduzidos ao simples "fazer". Experienciar, para ele, é viver determinadas condições que dão possibilidade para que a experiência se efetive.

A experiência não se basta como algo exterior ao sujeito, mas sinaliza uma interface entre interior e exterior; logo, o sujeito que a vive, no sentido arrogado por Larrosa (2002), permite que algo lhe aconteça, que algo lhe toque, que algo the suceda. $O$ sujeito da experiência é consciente de sua condição de construtor do seu conhecimento, de sua personalidade e de sua formação. Ao sujeito que vive a experiência, algo lhe acontece: ele não se informa simplesmente, ele passa a ser autor do processo de conhecer.

Para o autor supracitado,

A experiência, a possibilidade de que algo nos aconteça ou nos toque, requer um gesto de interrupção, um gesto que é quase impossível nos tempos que correm: requer parar para pensar, parar para olhar, parar para escutar, pensar mais devagar, olhar mais devagar, e escutar mais devagar; parar para sentir, sentir mais devagar, demorar-se nos detalhes, suspender a opinião, suspender o juízo, suspender a vontade, suspender o automatismo da ação, cultivar a atenção e a delicadeza, abrir os olhos e os ouvidos, falar sobre o que nos acontece, aprender a lentidão, escutar aos outros, cultivar a arte do encontro, calar muito, ter paciência e dar-se tempo e espaço. (Larrosa, 2002, p. 24).

Estes elementos, para o filósofo citado, são fundamentais para que o sujeito se torne capaz de experienciar. Notamos que isso não é simples e que o sujeito é o principal responsável por buscar criar condições de possibilidade para que algo lhe aconteça. O sujeito da experiência em Larrosa (2002) é aquele que tem a capacidade de olhar para seu tempo com paciência, com lentidão, com demora nos detalhes, num gesto de interrupção. Logo, o sujeito da experiência não é aquele que simplesmente executa a ação, que se informa e opina, que age por impulsos e desejos ou que participa de inúmeras atividades, mas é aquele que admite sua receptividade diante da experiência que vivencia.

Creio que as experiências vivenciadas pelos associados nesses dez primeiros anos de trocas de conhecimento entre pesquisadores mais experientes e novos pesquisadores possibilitaram a construção dos outros dez anos da Associação, em que esta foi amadurecendo suas experiências, inclusive na escolha das temáticas dos congressos e reuniões.

O VI Congresso da ABRACE ocorreu no estado de São Paulo (SP), no ano de 2008, com a temática "Arte Ciências: abismos de rosas" e implicou uma abertura às questões da ciência na busca de dimensionar os eventuais hiatos que possam existir frente às chamadas "hard ciências", ou entre a pesquisa em artes e aquela voltada para as ciências exatas (Ramos, 2012). 
A VI Reunião Científica e o VII Congresso ocorreram, respectivamente, em 2011 e 2012, na Universidade Federal do Rio Grande do Sul, com o apoio do Programa de Pós-Graduação em Artes Cênicas do Instituto de Artes e do Departamento de Arte Dramática daquela universidade. A reunião contou com duas conferências internacionais que enriqueceram sua programação: na abertura, o professor, crítico e historiador teatral argentino Jorge Dubatti abordou o tema "Teatro, convívio e tecnovívio"; depois, foi a vez de Christine Roquet, pesquisadora francesa e doutora em Dança, com o tema "Ao encontro da criação: a análise do movimento e o processo de criação coreográfica". O congresso contou com a presença massiva de pesquisadores de todos os programas de Pós-Graduação em Artes Cênicas, de Teatro e de Dança do Brasil, além de professores provenientes de diferentes universidades da América Latina.

Sob o tema "Tempos de memória: vestígios, ressonâncias e mutações", o evento foi palco de diferentes discussões, tais como a relação entre memória e criação; memória e re(apresentação); a memória da arte efêmera da cena. O debate foi enriquecido por palestras de convidados especiais. A conferência de abertura foi proferida pelo Prof. Dr. Ivan Izquierdo, um dos mais renomados cientistas brasileiros, especialista dos mecanismos biológicos envolvidos no funcionamento da memória. O Congresso contou ainda com a presença dos seguintes convidados estrangeiros: Ann Cooper Albright (Oberlin College, em Oberlin/EUA); José Antônio Sánchez (Universidad de Castilla, em La Mancha/Espanha), Alberto Kurapel e Susana Cáceres (Compagnies des Arts Exilio, em Santiago/Montréal) e Ana Carolina Ávila (Bogotá). Foram realizadas duas conexões via Skype: sobre o Projeto "Global Theatre Historie", com o professor Christopher Balme, da Universidade de Munique, com mediação de Maria Helena Werneck; e com o professor Hans-Thies Lehmann, da Universidade de Frankfurt, e com mediação de Stephan Baumgärtel, que abordou o tema "Esqueço sempre meu rosto: Brecht, o artista de várias identidades".

No ano de 2013, a Reunião Científica (VII) ocorreu na Universidade Federal de Minas Gerais, cujo tema foi “Arte da Cena: a pesquisa em diálogo com o mundo", e teve como foco a promoção, junto aos associados, de uma avaliação do estágio atual das colaborações traçadas entre pesquisadores da associação, as produções conjuntas realizadas e, também, descortinar novos modos de colaboração. Instaurando novos espaços de discussão entre os pesquisadores, essa reunião estabeleceu um importante fórum para repensar os encontros, as trocas que vêm ocorrendo e as que podem ainda ser estabelecidas entre os membros da Associação, bem como quais são as relações possíveis com a sociedade.

A VII Reunião Científica contou ainda com convidados internacionais, com o Prof. José Gil (Universidade Nova Lisboa), que fez a conferência de abertura "Arte da Cena: a pesquisa em diálogo com o mundo", e com a pesquisadora mexicana Patrícia Cardona (Instituto Nacional de Belas Artes), que proferiu a conferência "A Poética de Ensino, uma experiência na formação de artistas".

No ano seguinte, 2014, na mesma instituição que abrigou a reunião científica, sob o tema "Arte, corpo e pesquisa na cena: experiência expandida", foi realizado o 
VIII Congresso buscando pensar sobre o corpo como acontecimento nas artes da cena e na pesquisa: abrigo poético de convívio e sociabilidade. Mais de 800 pesquisadores, pós-graduandos e graduandos estiveram presentes. Além das sessões de Grupos de Trabalho, mesas-redondas e conferências de convidados internacionais, nesse congresso foi realizada a primeira Jornada de Novos Pesquisadores, buscando gerar novos espaços de diálogos para pós-graduandos em seus primeiros anos de participação na associação e no congresso.

O congresso contou com as conferências internacionais dos pesquisadores Jorge Larrosa (Universidad de Barcelona), Mark Franko (Temple University) e Bruce Barton (University of Calgary). Tais conferências foram intituladas, respectivamente: "Palavra Muda”, sobre linguagem, experiência e subjetividade; “Epílogo de um epílogo: historicizando e re-Reconstituição" e "Dramaturgia interactual: estratégias Interdisciplinares para criação de performance colaborativa".

Na VIII Reunião Científica realizada em 2015 na Universidade Federal de Uberlândia, em Minas Gerais, o objetivo foi promover uma avaliação do momento histórico e político da associação. Por isso, o tema da VIII Reunião Científica foi "ABRACE em questão: políticas do conhecimento em Artes Cênicas", que se propôs a problematizar as formas de criação, produção e socialização do conhecimento em Artes Cênicas no país e seus desdobramentos na vida acadêmica e na sociedade, pensando as zonas de disputa (simbólica, histórica, política) que emergem no cruzamento entre a investigação em nossa área e as políticas públicas para a Educação e pesquisa no Brasil.

Realizaram-se quatro Simpósios Temáticos, em diálogo com universidades da América Latina, por meio de convidados internacionais, ${ }^{2}$ que discutiram e socializaram suas pesquisas acerca das experiências de socialização de pesquisas de formas performativas, dos imbricamentos entre pesquisa e criação, da noção de prática como pesquisa no campo das Artes e das experiências em rede entre pesquisadores, especialmente no que se refere às publicações.

A partir do diálogo com os associados, por meio dos coordenadores de GT e pesquisadores em Dança, foram realizados fóruns de discussão a partir de quatro eixos de interesse dos associados: 1) Debate das políticas públicas para Educação, Artes e Pesquisa no país; 2) Debate das políticas de internacionalização da pesquisa, discutindo seus sentidos e nossas estratégias de diálogo e atuação política no Brasil; 3) Políticas editoriais da ABRACE e suas interfaces com as políticas editoriais brasileiras em nossa área; 4) Organização interna da associação e relações entre os diferentes sócios da ABRACE. Ainda dentro dessa temática, em 2016 realizou-se, na universidade que sediou a VIII Reunião Científica, o IX Congresso da ABRACE.

Ao completar dezoito anos de ABRACE, uma das buscas do IX Congresso foi colocar em pauta a inserção sociopolítica da associação, especialmente diante do

2 Dra. Patricia Aschieri (Universidade de Buenos Aires e Grupo de Pesquisa em Antropologia do Corpo e da Performance da UBA), Miguel Rubio Zapata (Grupo Yuyachkani), Maria Jose Contreras (PUC - Chile) e a Profa. Dra. Vivian Martinez Tabares (ISA/Casa das Américas). 
contexto do país vivenciado ao longo dos dois anos de gestão, seja nos debates ocorridos na VIII Reunião Científica, seja na participação e na produção de diversos documentos enviados a diferentes instâncias do poder público e, por fim, no IX Congresso da associação (Abrace, 2017).

O IX Congresso ABRACE teve como tema as "Poéticas e estéticas descoloniais: Artes Cênicas em campo expandido", alimentadas pelas perspectivas das epistemologias do sul. Nesse sentido, colocou-se em evidência o imbricamento entre criadores e suas produções a partir das relações sociopolíticas culturais de seus locais de origem, de etnia e de gênero, de um lado, e, simultaneamente, com a dissolução de territórios e fronteiras, conectando ações, performers e debates no campo da criação e da reflexividade sobre o próprio sentido das artes no contexto contemporâneo.

Ao sediar a Associação Brasileira de Pesquisa e Pós-Graduação em Artes Cênicas na gestão 2017-2018, a Universidade Federal do Rio Grande do Norte, com o apoio do seu Programa de Pós-Graduação em Artes Cênicas, teve a honra e o compromisso de promover a realização da IX Reunião Científica da ABRACE. Inicialmente, a realização do evento teve por propósito dar continuidade ao trabalho conjunto e contínuo de fortalecimento das Artes Cênicas brasileiras, da pesquisa acadêmica, tanto de caráter científico quanto artístico stricto sensu, e da qualificação dos pesquisadores da área, com base no êxito obtido nos eventos anteriores.

Nessa IX Reunião Científica, o objetivo foi promover uma avaliação do momento atual de nossa associação: de um lado, os modos como pensamos a criação e a produção de conhecimento, a organização interna e as relações dentro de nossa associação; de outro lado, os modos como nos posicionamos política e socialmente frente às ações e transformações nas políticas públicas brasileiras que nos tocam.

O tema proposto para a IX Reunião Científica da ABRACE coadunou com um movimento social e político atual de dar visibilidade para a diversidade de saberes que emerge da nossa cultura. No último Congresso da ABRACE, foram discutidas as poéticas e estéticas descoloniais, e isso abriu um precedente para aprofundar as discussões nos saberes artísticos e processuais, nos saberes acadêmicos e interculturais e nos saberes da terra e das identidades.

Em função desta discussão que se instaurou, a ABRACE propôs uma Reunião Científica que pensasse essa diversidade para, a partir disso, preparar o Congresso de 2018, que celebrou os 20 anos da Associação. Refletir sobre a diversidade é reconhecer a identidade da ABRACE, que é formada por pesquisadores de todas as partes do Brasil e que traz hoje 16 Grupos de Trabalho, que se constituem em torno dos mais variados temas: Etnocenologia, Artes Cênicas na Rua, Estudos da Performance, Processos de Criação e Expressão Cênica, História das Artes do Espetáculo, Dramaturgia, Tradição e Contemporaneidade, Teorias do Espetáculo e da Recepção, Pedagogia das Artes Cênicas, Territórios e Fronteiras, Mito, Imagem e Cena, Circo e Comicidade, Grupo de Pesquisadores em Dança, Cartografias de Pesquisa em Processo, Poéticas Espaciais Visuais e Sonoras, O Afro nas Artes Cênicas: Performances 
Afro-Diaspóricas em uma perspectiva de Descolonização, e Artes Performativas, Modos de Percepção e Práticas de Si.

O X Congresso que teve como temática "ABRACE: 20 anos celebrando a diversidade" contou com quase 600 pesquisadores das Artes Cênicas, entre doutores, mestres, doutorandos, mestrandos, alunos de iniciação científica e de graduação, além de mestres da cultura popular, discutindo esses saberes que urgem em um país que se mostra em devaneios de abismos.

Quando abordamos a questão da diversidade, estamos buscando refletir sobre o conceito de identidades, no plural, que começa a determinar lugares de fala e de ação na nossa sociedade. A partir deste aspecto, podemos nos reconhecer como pesquisadores, fazedores de arte e propositores de um pensamento político, estético e social, agentes capazes de produzir, pensar sobre e reconhecer a pluralidade no universo da pesquisa em Artes Cênicas. Deste modo, podemos fazer arte sob uma perspectiva pessoal e considerar a pertinência do trabalho do outro, podemos celebrar a diversidade e respeitar as diferenças, entendendo que cada qual tem o seu espaço e que juntos construímos uma identidade plural, legítima e multifacetada.

\section{O que temos realizado além das reuniões científicas e dos congressos?}

A ABRACE, além de realizar reuniões científicas e congressos, tem realizado, juntamente com seus associados, fóruns de coordenadores e editores, cartas e monções que digam respeito às Artes e às Artes Cênicas no país e suas relações com a situação política nacional; além de publicizar os artigos aprovados nos anais da associação, emitir notícias de concursos públicos na área das Artes Cênicas, seminários e congressos afins e, ainda, apoiar os eventos regionais que são frutos das discussões geradas nos Grupos de Trabalho.

Durante esses vinte anos de existência, publicou em formato de livro as palestras de convidados dos eventos, algumas mesas temáticas propostas pelos sócios e outros textos selecionados, a saber: Múltiplos olhares sobre processos descoloniais nas Artes Cênicas (2017), Arte, corpo e pesquisa na cena: experiência expandida (2016), Mapas e percursos, estudos da cena (2014), Tempos de memória (2013), Da cena contemporânea (2012), Arte e Ciência: abismos de rosas (2012), Ensaios em cena (2010) e Metodologias de pesquisa em Artes Cênicas (2006). Os livros citados foram organizados pelo comitê científico dos congressos realizados.

Os livros de caráter multifacetado e plural delineiam os contornos da Associação em torno das pesquisas da área feitas em solo brasileiro e em outras instituições de ensino internacional, a exemplo dos artigos de Jorge Dubati (Argentina), Hans-Thies Lehmamm (Alemanha), Óscar Cornago (Espanha), Jean-François Peyret, Josette Ferral, Isabelle Launay, Silvie Fortin, Christine Rrouquet (França), dentre outros. Dentro dessa seara da produção científica, desde o ano de 2007 o portal da ABRACE reúne os textos digitalizados dos congressos e das reuniões científicas. 


\section{Como a Associação tem discutido a questão docente?}

As questões docentes vêm sendo discutidas nos fóruns regionais e nos Grupos de Trabalho da ABRACE, em especial nos Encontros Nacionais de Pedagogia das Artes Cênicas, a exemplo da Carta Aberta em defesa da manutenção e da ampliação das políticas públicas na área de Artes Cênicas, dos debates e propostas para as políticas educacionais e a realidade do ensino de Artes Cênicas na escola e na comunidade. Os temas debatidos nesses encontros, a troca de experiências, os relatos de pesquisa e, sobretudo, o encontro de pesquisadores, pesquisadoras e estudantes com questões caras ao momento crítico em que a Educação Básica brasileira está vivendo não poderiam deixar de gerar as discussões no referido Encontro e de gerar suas cartas e monções, demarcando um posicionamento perante o avanço autoritário de decisões políticas que desprezam anos de luta por uma educação emancipatória.

Sobre a Carta Aberta, os pesquisadores responsáveis pelo evento, Vicente Concílio (UDESC) e Thiago Cruvinel (IFMG), esclarecem que o teor da carta discutia as condições de trabalho do professor de Arte, de Teatro e de Dança em suas diversas realidades nas unidades federativas, nos estados e nos municípios brasileiros, reforçando nossa preocupação e nossa indignação em relação às políticas públicas encaminhadas de forma autoritária pelo atual governo, principalmente na Reforma do Ensino Médio e na conclusão da Base Nacional Comum Curricular (BNCC). Além disso, a carta também enfatiza a necessidade da manutenção e da ampliação do Mestrado Profissional em Artes (Prof-Artes) e do Programa Institucional de Bolsas de Iniciação à docência (PIBID), projetos que já conseguiram, por meio dos resultados apresentados, modificar a realidade do ensino de Artes Cênicas nas escolas e na comunidade e da ampliação e da criação de concursos específicos na área, nas esferas federal, estadual e municipal, em consonância com a LDB, como política pública para o cumprimento da lei e para oportunizar a entrada, no mundo do trabalho, dos formandos em Licenciatura em Artes Cênicas.

No GT Pedagogia das Artes Cênicas, são discutidas as pesquisas que tratam do ensino brasileiro, em especial das Artes Cênicas, e são apresentadas propostas ao poder público via ABRACE para o fortalecimento do ensino de Arte no país. Além do GT citado, as discussões transversalizam o Grupo de Pesquisadores em Dança, que, ao longo de sua existência, tem tratado do ensino da Dança na Educação Infantil, nos ensinos Fundamental e Médio e na educação superior. Esse grupo tem, assim como o de Pedagogia das Artes Cênicas, discutido a situação do ensino da dança no espaço escolar em encontros realizados na Unicamp e que tem gerado debates acerca dos desmontes do ensino de Arte/Dança na escola.

Assim, a partir do GT Pedagogia das Artes Cênicas e do Grupo de Pesquisadores em Dança, as pesquisas que tratam da questão docente e do fortalecimento do ensino de Artes no país vêm sendo discutidas e levadas a público a partir dos debates 
de seus participantes, dos encontros regionais e nacionais e das cartas e monções encaminhadas aos poderes públicos do país.

Entende-se nesses espaços as Artes Cênicas como um campo específico do saber, que, atrelado a outros campos em processos necessários de permuta e hibridização, acaba por diferenciar-se dos demais ao constituir suas regras e modos de procedimento de produção, circulação e recepção dos artefatos que produz. Assim, compreendo as Artes Cênicas em suas relações educacionais como uma linguagem (e um campo do saber), que na ABRACE é entendida como linguagem autônoma a ser aprendida, desenvolvida e experienciada nos campos do saber já institucionalizados e tradicionais na construção de conhecimento, assim como em outros espaços não formais de ensino/aprendizagem.

Esses grupos de trabalho têm ainda discutido a formação do professor nas Artes Cênicas. Essa discussão não é novidade, a discussão sobre a formação de professores no cenário brasileiro não se constitui em uma temática recente, posto que, desde a década de 1980, se ela tornou uma das questões centrais do campo educacional.

Mais especificamente no campo das Artes Cênicas/Educação, o marco histórico do surgimento do processo de formação de professores para o ensino de Artes Cênicas no Brasil não está relacionado à Lei de Diretrizes e Bases da Educação Nacional, Lei $n^{\circ} 5.692 / 71$, que estabelece a obrigatoriedade do ensino de arte nas escolas de $1^{\circ}$ e $2^{\circ}$ graus e a criação dos cursos de Licenciatura Curta em Educação Artística, na década de 1970.

Sobre a formação docente nas Artes Cênicas, Silva (2008) fez um levantamento na Memória ABACE I e IX, encontrando 12 estudos publicados entre os anos de 1999 e 2007. O autor verificou também que todos os artigos foram publicados na primeira década do século XXI. Esses dados corroboram com os estudos no campo da formação de professores, ao afirmarem que só a partir da década de 1990, do século XX, o campo da formação de professores passou a ser considerado como uma área estratégica para o avanço dos índices de qualidade da educação escolar, constituindo-se como um campo prioritário da agenda governamental e da política pública em Educação. Esses estudos buscaram compreender e problematizar a formação dos professores, em especial para o ensino de Teatro, a partir de diferentes perspectivas.

Silva (2008) diz que os dados revelaram ainda muitos aspectos silenciados em torno e nas margens desses artigos, dos quais ele cita

A construção da identidade e profissionalização do professor para o ensino de Teatro; a escola como local privilegiado da formação e a prática pedagógica como conteúdo institucionalizado para a formação docente; a questão da experiência na formação de professores e a produção de saberes docentes para o ensino de teatro; a utilização das novas tecnologias e da Educação a Distância no percurso formativo dos professores; estudos que estabelecem uma relação de comparação com os modelos formativos de outros países; a formação do 
professor de teatro que atua em organizações educacionais, não escolares, tais como Organizações Não-Governamentais (ONGs), os museus, Teatros, hospitais, livrarias e as instituições culturais de uma forma geral; o princípio da interculturalidade e da interdisciplinaridade na formação do professor para o ensino de Teatro; a formação para o ensino de Teatro de professores leigos e dos professores que atuam na Educação de Jovens e Adultos, em classes multisseriadas e no meio rural (Educação no Campo); a formação de professores de teatro para atuação na educação especial; a formação dos formadores dos professores de teatro no Brasil; a questão da polivalência na formação do professor de teatro; a formação inicial para o ensino de Teatro nos cursos Normal Médio e Pedagogia; acesso a formação, carreira, remuneração e condições de trabalho; as políticas públicas em educação voltadas para a formação professores para o ensino de Teatro. (Silva, 2008, p. 3-4).

Os resultados dessa pesquisa, feita nos idos de 2008, apontaram que, apesar de uma produção relevante, ela ainda não era significativa, pois, mesmo com o avanço conceitual apresentado por esses estudos, o número de publicações encontradas não é representativo diante da necessidade de melhor compreender e nortear esse fenômeno tão complexo em um país de dimensão continental e com tantas especificidades regionais e locais.

Certamente houve avanços na produção cientifica no que concerne à produção da formação docente nas Artes Cênicas de 2008 a 2018, posto que as pesquisas foram se sedimentando, outras foram surgindo, e o campo epistêmico foi evoluindo com o refletir da questão docente na Associação. O volume de comunicações de pesquisa nesses congressos e reuniões foi expressivo e significativo. Sabemos, entretanto, por meio de nossos representantes, junto aos órgãos de fomento, que a pesquisa em Artes Cênicas ainda é avaliada como inconsistente no que tange à sua sistematização.

\section{que virá?}

Talvez não saibamos o que virá, mas por certo diremos que muitas contradanças, teatros, apresentações circenses e de performance ocorrerão nessa Associação entre pesquisadores experientes e novos pesquisadores em Artes Cênicas.

As Reuniões Científicas e os Congressos já realizados atraíram a atenção de uma plateia concorrida e comprometida com o desenvolvimento da pesquisa em Artes Cênicas no Brasil, acolhendo um número significativo de professores, artistas, estudantes e membros dos programas brasileiros e estrangeiros de pesquisa e pós-graduação na área, computando cerca de 40 universidades e núcleos de pesquisa em artes cênicas representados.

A publicação da série Memória ABRACE (I, II, III, IV, V, VI, VII, VIII, IX e X) sedimenta e amplia esse grande "fórum" em que se constitui a $A B R A C E$, transformando esse rol 
de publicações em referência de consulta para a produção acadêmica em desenvolvimento na área, no Brasil.

A dança, o teatro, o circo, a performance como produção do conhecimento nos Congressos da ABRACE podem contribuir para um conhecimento de nossa realidade em diferentes âmbitos, seja como referência da cultura local, regional, nacional ou internacional. O necessário é reconhecer que fazemos parte desta realidade e considerar que estamos fazendo história a cada dia, que construímos os significados de nossas vidas a cada aula e, talvez, a cada nova composição coreográfica.

Acreditamos que, para se fazer ou produzir dança, circo, performance e teatro, é necessário, ou desejável, que se tenha presente o transcurso já realizado por outras pessoas, artistas, pesquisadores nos Congressos da ABRACE. É preciso perceber e analisar de que maneira as inter-relações artísticas, estéticas, corporais, técnicas, expressivas e de ensino vem ocorrendo ao longo do processo histórico-cultural das Artes Cênicas nessa associação.

\section{Referências}

ABRACE. Como pesquisamos? In: CONGRESSO BRASILEIRO DE PESQUISA E PÓSGRADUAÇÃO EM ARTES CÊNICAS, 2., 2001, Salvador. Anais [...]. Salvador, BA, 2001.

ABRACE. IV Reunião Científica de Pesquisa e Pós-Graduação em Artes Cênicas. Rio de Janeiro, RJ, 2007.

ABRACE. Os trabalhos e os dias das artes cênicas: ensinar, fazer e pesquisar dança e teatro e suas relações. In:CONGRESSO BRASILEIRO DE PESQUISA E PÓS-GRADUAÇÃO EM ARTES CÊNICAS, 4., 2006, Rio de Janeiro. Anais [...]. Rio de Janeiro: 7 Letras, 2006.

ABRACE. Memória Abrace XVI. In: CONGRESSO DA ASSOCIAÇÃO BRASILEIRA DE PESQUISA E PÓS-GRADUAÇÃO EM ARTES CÊNICAS, 9., 2017, Uberlândia. Anais [...]. Uberlândia: UFU, 2017.

ABRACE. Homepage. Disponível em: http://portalabrace.org/portal/. Acesso em: 20 jun. 2018.

IZQUIERDO, I. Memória. Porto Alegre: Artmed, 2002.

LARROSA, J. Notas sobre a experiência e o saber de experiência. Revista Brasileira de Educação, ANPED, n. 19, jan./abr. 2002.

RAMOS, L. F. (org.). Arte e Ciências: abismos de rosas. São Paulo: ABRACE, 2012. 
RICOER, P. A memória, a história, o esquecimento. Campinas: Editora da Unicamp, 2007.

SILVA, E. M. A. O que dizem os artigos publicados nos "memória abrace" sobre a formação de professores para o ensino de teatro? In: CONGRESSO DA ASSOCIAÇÃO BRASILEIRA DE PESQUISA E PÓS-GRADUAÇÃO EM ARTES CÊNICAS, 5., 2008, Belo Horizonte. Anais [...]. Belo Horizonte, 2008. 